See Article page XXX.

\section{Commentary: Patients and caregivers may have different expectations from operations}

\author{
Victor A. Ferraris, MD, PhD
}

There is a spectrum of patient and caregiver expectations when they are faced with choices about having an operation. As a US Army infantry officer, I was wounded in combat (Figure 1) and I had absolute faith in the surgeon who treated me. I expected that whatever the doctor would do was the best chance that I had to survive and flourish. There were no doubts, no questions, and I don't remember signing a consent form. Later after my medical training (supplied by the Army), I remember being a bit surprised when patients, especially older patients who were retired soldiers, would ask questions that had an element of uncertainty and even suspicion regarding a planned operation. I would ask these patients about this element of uncertainty, and I came to understand that most of these questions were related to quality of life following the operation. Would they be able to eat normally? Could they walk and play golf like they did before the operation? Surgeons are understandably focused on hard outcomes: operative mortality, wound infections, pneumonia, and renal failure. Patients are certainly aware that good outcomes are preferable, but not always guaranteed. Patients are prepared to ask preoperative questions about quality of life and other less-concrete outcome measures, but for the most part surgeons are not very forthcoming about addressing these types of questions.

Oravec and colleagues ${ }^{1}$ attempt to address this gap between hard outcomes of operations (eg, mortality, wound infection, and pneumonia) and softer outcomes that deal with quality-of-life issues. This work is not in the

\footnotetext{
From the Division of Cardiothoracic Surgery, Department of Surgery, Lexington VA Medical Center and University of Kentucky, Lexington, Ky.

Disclosures: The author reported no conflicts of interest.

The Journal policy requires editors and reviewers to disclose conflicts of interest and to decline handling or reviewing manuscripts for which they may have a conflict of interest. The editors and reviewers of this article have no conflicts of interest.

Received for publication Dec 4, 2021; revisions received Dec 4, 2021; accepted for publication Dec 7, 2021.

Address for reprints: Victor A. Ferraris, MD, PhD, Division of Cardiothoracic Surgery, Department of Surgery, Lexington VA Medical Center and University of Kentucky, Room B504, 1101 Veterans Dr, Lexington, KY 40502-0284 (E-mail: ferraris@uky.edu).

J Thorac Cardiovasc Surg 2021; $\mathbf{\square}: 1-2$

$0022-5223 / \$ 36.00$

Copyright (c) 2021 by The American Association for Thoracic Surgery

https://doi.org/10.1016/j.jtcvs.2021.12.016
}

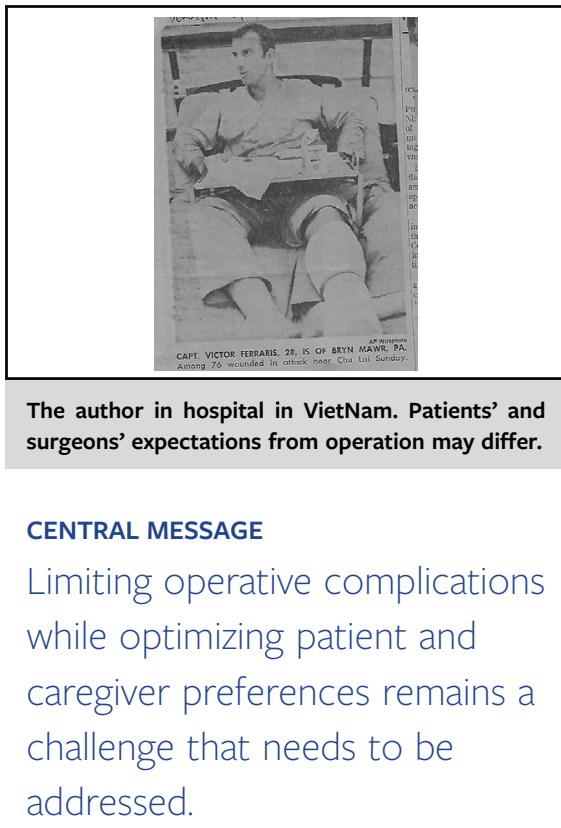

prototypical realm of articles that appear in our thoracic surgical journals. This article deals with soft science in that the authors attempted to review how patients and caregivers want a cardiothoracic operation to turn out. The authors ultimately want a synthesis of these patient-treatment preferences and assessments of outcomes to serve as background for future studies to optimize patient outcomes while investigating enhanced patient preferences that may have an influences on hard surgical outcomes.

There are a few things that seem obvious when considering ideal outcomes of operations. Patients want to survive an operation. They want to be in good shape, which means they want to be able to do things. This is a soft reflection of functional status. It is a minority of patients who ask indepth questions about postoperative functional capacity. $\mathrm{Pa}-$ tients want to avoid complications, especially those that limit activity and affect well-being. There is an important limitation in the article by Oravec and colleagues ${ }^{1}$ that revolves around the fact that patients were not directly approached about what they want from an operation. Had patients been sampled individually, I'm sure that the responses would cover a wide range and would be very hard to solidify into a cohesive, understandable path to optimize surgical outcomes while still favoring patient preferences. The authors were only able to summarize patient and caregiver preferences from literature reviews and secondary sources. It seems obvious that each patient might have a 


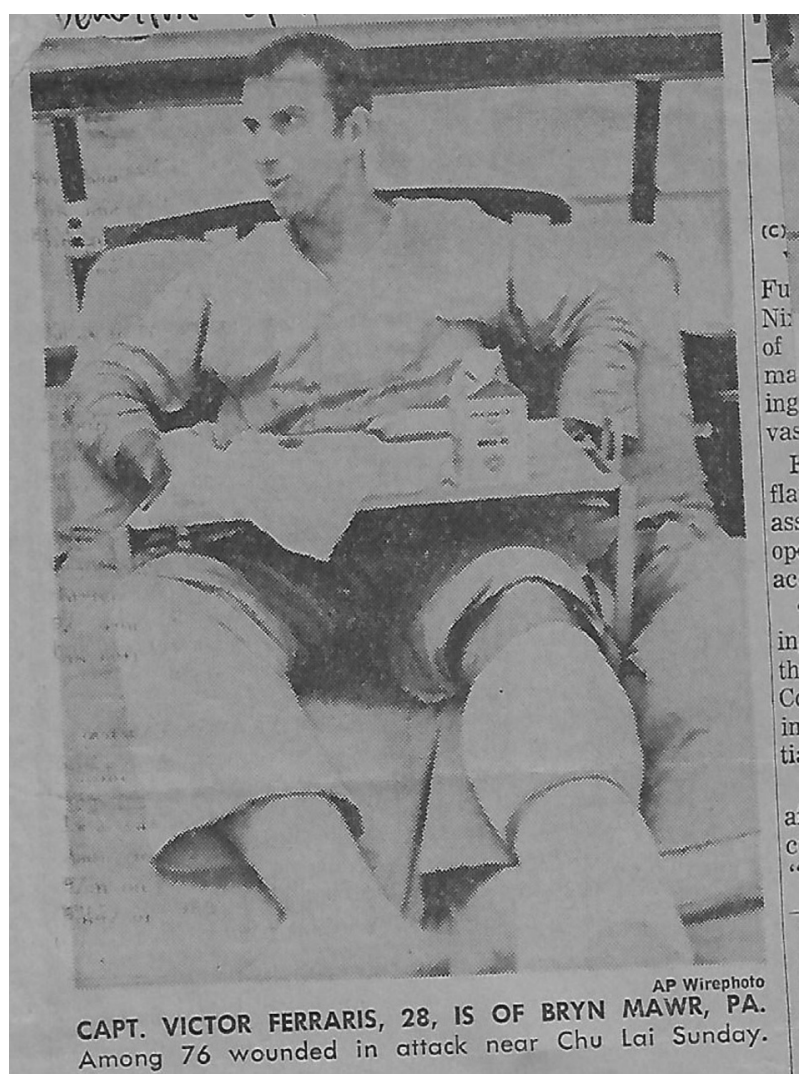

FIGURE 1. The author in hospital in VietNam. Patients' and surgeons' expectations from operation may differ. slightly different expectation and understanding of what is possible from an operation and what to expect during the recovery phase of an operation. It is apparent that the authors' scoping review serves as groundwork for future studies to address key elements of the recovery phase of operations, and to create a comprehensive understanding of how to optimize outcomes and also provide optimal caregiver and patient preferences. This article will serve as a bellwether for future studies that address synchronizing patient recovery preferences with optimal hard outcomes.

\section{Reference}

1. Oravec N, Arora RC, Bjorklund B, Gregora A, Monnin C, Dave MG, et al. Patient and caregiver preferences and prioritized outcomes for cardiac surgery: a scoping review and consultation workshop. J Thorac Cardiovasc Surg. 2022. XXX:XXX. 